\title{
PENGARUH CELEBRITY ENDORSER DAN BRAND IMAGE TERHADAP KEPUTUSAN PEMBELIAN LUWAK WHITE KOFFIE
}

\author{
(Studi Warung Nasi Pemalang, Jakarta Timur)
}

\author{
Chusnah \\ Ahmad Zaenuri \\ Fakultas Ekonomi dan Bisnis Program Studi Manajemen \\ Universitas Islam As-Syafi'iyah \\ chusnahchoyib@yahoo.com
}

\begin{abstract}
This study aims to determine the effect of Celebrity Endorser and Brand Image on the Purchase Decision of Luwak White Koffie at Pemalang Rice Stalls. This research was conducted on Luwak White Koffie consumers, the sample used was 55 consumers. Hypothesis testing uses validity and reliability, normality test, multicollinearity test, heteroscedasticity test and autocorelas test. The analysis used is regression and correlation analysis, Determination of the $t$ test and $f$ test, based on the results of data analysis and discussion, partially celebrity endorser has an insignificant and positive effect on purchasing decisions with a tcount of 0.386 indicating that a significance level of $0.701>0.05$ and tcount $0.386<t$ table 2.007 , brand image partially significant and positive effect with tcount of 2.219 indicates that the significance level of $0.031<0.05$ and tcount of 2.219> $t$ table 2.007. the coefficient of determination of 0.122 means the percentage contribution of the influence of variable $X$ to $Y$ by $12.2 \%$ while the remaining $87.8 \%$ is influenced by other variables.
\end{abstract}

\section{Keywords: Celebrity Endorser, Brand Image and Purchasing Decisions}

Abstrak : Penelitian ini bertujuan untuk mengetahui pengaruh Celebrity Endorser dan Brand Image Terhadap Keputusan Pembelian Luwak White Koffie pada Warung Nasi Pemalang. Penelitian ini dilakukan pada konsumen Luwak White Koffie, sampel yang digunakan adalah 55 konsumen. Pengujian hipotesis menggunakan uji validitas dan reabilitas, uji normalitas, uji multikolinearitas, uji heteroskedastisitas dan uji autokorelas. Analisis yang digunakan adalah analisis regresi dan korelasi, Deteminasi uji t dan uji $f$, berdasarkan hasil analisis data dan pembahasan, secara parsial celebrity endorser berbengaruh tidak signifikan dan positif terhadap keputusan pembelian dengan $t_{\text {hitung }}$ sebesar 0,386 menunjukkan bahwa tingkat signifikansi $0,701>0,05$ dan $t_{\text {hitung }} 0,386<$ $t_{\text {tabel }} 2.007$, brand image secara parsial berpengaruh signifikan dan positif dengan $t_{\text {hitung }}$ sebesar 2,219 menunjukkan bahwa tingkat signifikansi $0,031<0,05$ dan $t_{\text {hitung }} 2,219>$ ttabel 2.007. Koefisien determinasi sebesar 0,122 artinya presentase sumbangan pengaruh variabel X terhadap Y sebesar 12,2\% sedangkan sisanya sebesar 87,8\% dipengaruhi oleh variabel lain.

Kata Kunci : Celebrity Endorser, Brand Image dan Keputusan Pembelian 


\section{PENDAHULUAN \\ 1.1 Latar Belakang}

Persaingan dalam industri minuman instan di Indonesia membuat perusahaan harus melakukan berbagai cara untuk memasuki persaingan dunia bisnis tersebut, agar dapat bertahan dan tidak kalah bersaing dengan perusahaan lainnya. Berbagai strategi harus dipersiapkan oleh perusahaan untuk merespon dan mengungguli para perusahaan pesaing yang juga memiliki keunggulannya masing-masing. Strategi yang harus dilakukan oleh para pelaku bisnis adalah dengan menggunakan strategi pemasaran.

Belakangan ini banyak perusahaan yang muncul dengan membuat merek kopi instan baru untuk ikut bersaing dalam bisnis kopi instan di Indonesia. Hal ini dikarenakan masih tersedianya peluang untuk mendapatkan market share di sektor bisnis kopi instan di Indonesia. Di Indonesia tidak asing lagi mendengar produk white coffee. Produk-produk white coffee antara lain adalah Luwak White Koffie, ABC White Coffee, TOP White Coffee dan Kapal Api White Coffee.

White Koffie merupakan produk baru dari kopi Luwak produksi PT. Java Prima Abadi yang mulai memasuki deretan kopi sachet indonesia pada tahun 2013. Luwak White Koffie merupakan kopi bubuk puth yang pertama kali masuk ke indonesia, dengan genre baru dan unik kopi putih yang beraroma nikmat dan aman dilambung dan jantung.

Front consulting grup setiap tahun mengeluarkan hasil Top Branding Award, Penghargaan yang diberikan kepada merek-merek yang meraih predikat TOP. Salah satu majalah marketing pada tahun 2017, merek Luwak White Koffie meraih "TOP Brand 2017" di Indonesia. Luwak white koffie menjadi jawara di katagori "White Coffee" dengan $68.5 \%$, mengalahkan merek-merek white coffee lainya.

Perusahaan harus dapat mengkomunikasikan produknya secara tepat dan cepat. Perusahaan perlu memberikan informasi yang jelas agar menimbulkan ketertarikan konsumen terhadap produk yang ditawarkan. Perusahaan dapat melakukan promosi produk melalui Iklan, Iklan merupakan salah satu bauran promosi yang digunakan sebagai alat pengantar pesan untuk membentuk sikap konsumen. Media yang digunakan adalah televisi, Radio, majalah, atau surat kabar.

Menurut Kotler dan Keller (2016:202) mengemukakan bahwa Pemasar harus memberi konsumen sesuatu isyarat positif agar konsumen selalu mengingat merek tersebut, dengan penggunaan Celebrity Endorser, kemasan yang menarik, dan promosi yang menarik diharapkan konsumen dapat mengingat suatu merek.

Oleh karena itu perusahaan diharapkan untuk mempertahankan serta meningkatkan citra merek yang yang dimiliki perusahaan, sehingga Brand Image dapat mempengaruhi keputusan pembelian konsumen. Ketika konsumen mulai yakin dengan pilihannya terhadap produk, maka akan muncul sikap ingin memiliki dengan muncul niat pembelian dan akhirnya konsumen akan melakukan keputusan pembelian.

Selebriti sangat berperan dalam membantu kelancaran aktivitas pemasaran, hal ini dikarenakan hubungan emosional yang tercipta lebih kuat dengan konsumen, serta bisa membangun daya tarik merek dengan target pasar yang dituju. Selebriti secara tidak langsung dapat membantu konsumen membeli suatu merek produk dengan mengaitkan pencitraaan dirinya yang membintangi iklan dari produknya yang dibelinya. Dengan adanya merek semakin memudahkan para konsumen dalam mengingat dan membandingkan dengan produk yang lain. 
Tjiptono (2015:49) menyatakan bahwa "Brand Image ialah deskripsi asosiasi dan keyakinan konsumen terhadap merek tertentu". Semakin baik brand image yang melekat pada produk yang diproduksi sebuah perusahaan, konsumen akan semakin tertarik untuk memutuskan membeli produk tersebut karena konsumen beranggapan bahwa suatu Produk dengan brand yang sudah terpercaya lebih memberikan rasa aman ketika akan menggunakannya. Sebuah perusahaan harus berupaya membangun brand image secara terus-menerus agar brand yang diciptakan menjadi lebih dipilih dan konsumen menjadi loyal terhadap brand tersebut.

Dari uraian latar belakang dari seluruh uraian diatas penulis tertarik untuk melakukan penelitan dengan judul: "Pengaruh Celebrity Endorser dan Brand Image terhadap Keputusan Pembelian Luwak White Koffie (Studi kasus pada Warung Nasi Pemalang, Jakarta Timur)"

\subsection{Rumusan Masalah}

1. Bagaimana gambaran Celebrity Endorser, Brand Image dan Keputusan Pembelian Luwak White Koffie?

2. Bagaimana pengaruh peran Celebrity Endorser terhadap Keputusan Pembelian Luwak White Koffie?

3. Bagaimana pengaruh peran Brand Image terhadap Keputusan Pembelian Luwak White Koffie?

4. Bagaimana pengaruh Celebrity Endorser dan Brand Image terhadap Keputusan Pembelian Luwak White Koffie?

\subsection{Tujuan Penelitian}

1. Untuk mengetahui gambaran Celebrity Endorser, Brand Image dan Keputusan Pembelian Luwak White Koffie.

2. Untuk mengetahui seberapa besar pengaruh Celebrity Endorser terhadap Keputusan Pembelian Luwak White Koffie.

3. Untuk mengetah seberapa besar pengaruh Brand Image terhadap Keputusan Pembelian Luwak White Koffie.

4. Untuk mengetahui seberapa besar pengaruh Celebrity Endorser dan Brand Image terhadap Keputusan Pembelian Luwak White Koffie

\subsection{Manfaat Penelitian}

1. Manfaat Teoritis

1. Hasil dari penelitian ini diharapkan dapat menjadikan sumbangan pemikiran dalam memperkaya wawasan dalam pengaruh Celebrity Endorser dan Brand Image terhadap Keputusan Pembelian.

2. Penelitan ini dapat digunakan untuk menambah referensi perpusakan bagi mahasiswa yang juga akan melakukan penelitan terhadap pengaruh Celebrity Endorser dan Brand Image di masa yang akan datang.

2. Manfaat Praktis

1. Bagi peneliti

a. Dengan penelitian ini diharapkan peneliti dapat menerapkan ilmu yang di peroleh selama perkuliahan dan menambah pengalaman. 
b. Sebagai sarana untuk menerapkan pengetahuan tentang Celebrity Endorser dan Brand Image. dan diberi literatur-literatur lain, serta membandingkan dengan kenyataan yang terjadi sebenarnya.

2. Bagi perusahaan

Diharapkan dapat menjadi bahan pertimbangan dalam rangka pemilihan endorser personaliti yang tepat, sehingga dapat mempengaruhi pembentukan citra merek.

\section{TINJAUAN PUSTAKA DAN HIPOTESIS}

\subsection{Tinjauan Teoritis}

\subsubsection{Teori Pemasaran}

Pemasaran merupakan salah satu bagian yang paling penting dalam suatu perusahaan. Pemasaran merupakan kegiatan pokok yang dilakukan perusahaan untuk mempertahankan kelangsungan hidupnya, karena memiliki fungsi untuk mencari, mendapatkan, mempertahankan, dan memperbanyak konsumen serta menguasai pasar.

Sunyoto (2014:39) mengemukakan bahwa pasar adalah organisasi yang menggambarkan semua pembeli dan penjual yang terlibat dalam transaksi aktual atau potensial terhadap barang atau jasa yang ditawarkan.

Dalam proses kegiatan pemasaran perusahaan dituntut untuk menciptakan komunikasi kepada konsumen, perusahaan memberikan kebutuhan sesuai dengan kebutuhan konsumen sehingga memberikan nilai atau keuntungan bagi perusahaan. Dengan begitu, perusahaan harus terus memberikan apa yang konsumen inginkan untuk memberikan kepuasan bagi konsumen sehingga akan memberikan keuntungan bagi perusahaan.

Kesuksesan yang diraih oleh pemasaran bukan secara kebetulan, namun terdapat proses kegiatan yang bertahap yang dilaksanakan dengan cermat sehingga dapat mencapai kesuksesan terutama keuntungan bagi perusahaan. Dengan keuntungan yang diperoleh dapat mepertahankan keberlangsungan perusahaan agar terus berjalan dan bersaing.

Tjiptono (2014:41) menyatakan bahwa Bauran pemasaran adalah seperangkat alat, yang dapat digunakan pemasar untuk membentuk suatu karakteristik jasa yang ditawarkan kepda pelanggan."

Bauran pemasaran/Marekting mix ada 9 elemen yang sudah dikembangkan oleh pakar ekonomi, yaitu: Product (Produk), Price (Harga), Place (Tempat), Promotion (Promosi), People (Orang), Physical Evidence (Bukti fisik), Proces (Process), Custemer service (Pelayanan Pelanggan), Payment (Pembayaran)

\subsubsection{Teori Celebrity Endorser}

Komunikasi yang dibangun oleh perusahaan kepada konsumennya adalah dengan cara komunikasi persuasif, komunikasi ini digunakan dengan menggunakan Celebrity Endorser untuk mengiklankan produknya, agar konsumen mengetahui produk yang ditawarkan. Pemasar harus memberi konsumen sesuatu isyarat positif agar konsumen selalu mengingat merek tersebut, dengan penggunaan Celebrity Endorser, kemasan yang menarik, dan promosi yang menarik diharapkan konsumen dapat mengingat suatu merek, menurut Kotler dan Keller (2016:202).

Dukungan selebriti telah lama digunakan oleh pemasar untuk meningkatkan daya tarik suatu merek, di mana selebriti biasanya diartikan sebagai orang yang dikenali dan 
dikontrak untuk mengiklankan suatu produk atau merek. celebrity endorser juga dapat dikatakan merupakan elemen terpenting dalam mempromosikan suatu merek ataupun suatu produk agar mudah untuk dikenal oleh konsumen.

Selebritis yang memiliki popularitas yang tinggi, kreadibilitas, bakat dan karisma memberikan manfaat bagi perusahaan. Oleh karena itu tantangan besar yang harus dilakukan oleh pemasar adalah membentuk citra merek yang kuat. celebrity endorser merupakan salah satu elemen yang terpenting dalam mempromosikan suatu produk, agar produk yang ditawarkan mudah untuk dikenal oleh konsumen. Endorser yang ditunjuk oleh perusahaan harus memiliki citra positif yang juga memiliki karakteristik yang sesuai dengan produk sehimgga dapat menarik banyak kalangan masyarakat karena mampu dengan mudahnya mempengaruhi seseorang untuk dapat mengkonsumsi suatu produk.

\subsubsection{Teori Brand Image}

Brand image berhubungan dengan sikap berupa keyakinan dan preferensi terhadap suatu merek. Konsumen yang memiliki citra yang positif terhadap suatu merek, akan lebih memungkinkan untuk melakukan pembelian terhadap suatu produk.

Tjiptono (2015: 49) menyatakan bahwa Brand Image ialah deskripsi asosiasi dan keyakinan konsumen terhadap merek tertentu. Dengan adanya brand semakin memudahkan para konsumen dalam mengingat dan membandingkan dengan produk yang lain. Semakin baik brand image yang melekat pada produk yang diproduksi sebuah perusahaan, konsumen akan semakin tertarik untuk memutuskan membeli produk tersebut karena konsumen beranggapan bahwa suatu produk dengan brand yang sudah terpercaya lebih memberikan rasa aman ketika akan menggunakannya.

\subsubsection{Teori keputusan Pembelian}

Keputusan pembelian merupakan proses dalam pembelian nyata setelah melalui tahap-tahap tertentu, kegiatan yang secara langsung terlibat dalam mendapatkan dan mempergunakan barang yang ditawarkan.

Schiffman Kanuk dalam (Sumarwan, 2015:357) menyatakan bahwa: keputusan pembelian adalah suatu keputusan sebagai pemilihan suatu tindakan dari dua atau lebih pilihan alternatif. Sedangkan menurut Setiadi dalam (Sangadji dan Sopiah, 2013:121) Menyatakan bahwa: pengambilan keputusan konsumen adalah proses pengintegrasian yang mengkombinasikan pengetahuan untuk mengevalusi dua perilaku alternatif atau lebih, dan memilih salah satu diantaranya. Hasil dari proses pengintegrasian tersebut merupakan suatu pilihan yang disajikan secara kognitif sebagai keinginan berperilaku.

Berdasarkan uraian menurut para ahli keputusan pembelian dapat disimpulkan bahwa keputusan pembelian adalah suatu tindakan atau pengambilan keputusan seseorang dalam memilih salah satu tindakan atau satu dari dua atau lebih pilihan tersedia sesuai dengan kebutuhan dan keinginan konsumen.

\subsubsection{Tinjauan Hasil Penelitian Terdahulu}

Dinda Yulia Hafisa (2018), dengan judul "Pengaruh Celebrity Endoerser terhadap Minat Beli Produk Kosmetik Halal "Wardah Di Yogyakarta" Dengan hasil penelitian, bahwa celebrity endorser berpengaruh positif terhadap daya tarik iklan, sebesar 0,038 lebih kecil dari tingkat signifikan $\alpha=5 \%$ atau $(0,038<0,05)$, dan daya tarik iklan berpengaruh positif terhadap minat pembelian. 
1. Yohanes Aditya (2016), dengan judul "Pengaruh Celebrity Endorser Cristiano Ronaldo dan Brand Image Terhadap Keputusan Pembelian Konsumen Shampoo Clear di Surabaya. Variable attractiveness dan credibility secara bersama-sama berpengaruh positif dan signifikan terhadap brand image shampoo clear dan variable credibility merupakan variable yang paling signifikan $(0.02<0.05)$ mempengaruhi brand image shampoo clear.

2. Muhammad David Hendra (2018), dengan judul Pengaruh Kreatifitas Iklan melalui pengunaan Endorser Pocari Sweat untuk Aplikasi Smartphone Terhadap Minat Beli Komunitas. Terdapat pengaruh positif variable kreatifitas iklan melalui penggunaan endorser (kradibilitas, keselarasan, kejelasan, dan multiple brand) yang dimiliki oleh endorser terhadap minat beli,dengan nilai signifikan $0.01<$ 0.05 .

3. Sri Nuryani (2014), dengan judul Analisis Pengaruh Iklan, Citra Merek dan Harga terhadap Keputusan Pembelian Sampo Sunsilk di Semarang. Hasil dari penelitian menunjukan bahwa variabel iklan, citra merek dan harga berpengaruh positif dan signifikan $(0.025<0.050)$ terhadap variabel keputusan pembelian Sampo Sunslik.

4. Iqbal Firdaus (2015), dengan judul "Pengaruh Celebrity Endorser terhadap Keputusan Pembelian Mahasiswa Universitas Widiyatama pada Brodo Footwear Bandung" Dengan hasil penelitian, Celebrity endorser berpengaruh signifikan terhadap minat beli konsumen pada produk Brodo dengan kontribusi yang diberikan sebesar 50,9\%.

\subsection{Hipotesis}

\subsubsection{Pengaruh Celebrity Endorser Terhadap Keputusan Pembelian}

Kotler dan Keller (2016:202) mengemukakan bahwa Pemasar harus memberi konsumen sesuatu isyarat positif agar konsumen selalu mengingat merek tersebut, dengan penggunaan Celebrity Endorser, kemasan yang menarik, dan promosi yang menarik diharapkan konsumen dapat mengingat suatu merek.

Adapun Penelitian yang dilakukan Iqbal Firdaus (2015), dengan judul Pengaruh Celebrity Endorser terhadap Keputusan Pembelian Mahasiswa Universitas Widiyatama pada Brodo Footwear Bandung menyatakan bahwa Celebrity Endorser berpengaruh pada Keputusan Pembelian.

Berdasarkan teori dan penelitian terdahulu maka hipotesis pertama sebagai berikut:

H1: Celebrity Endorser berpengaruh terhadap Keputusan Pembelian

\subsubsection{Pengaruh Brand Image Terhadap Keputusan Pembelian}

Tjiptono (2015:49) menyatakan bahwa "Brand Image ialah deskripsi asosiasi dan keyakinan konsumen terhadap merek tertentu". Semakin baik brand image yang melekat pada produk maka konsumen akan semakin tertarik untuk memutuskan membeli produk tersebut, karena konsumen beranggapan bahwa suatu Produk dengan brand yang sudah terpercaya lebih memberikan rasa aman ketika akan menggunakannya.

Adapun penelitian yang dilakukan Sri Nuryani (2014), dengan judul Analisis Pengaruh Iklan, Citra Merek dan Harga terhadap Keputusan Pembelian Sampo Sunsilk di Semarang menyatakan bahwa Brand image berpengaruh terhadap Keputusan Pembelian.

Berdasarkan teori dan penelitian terdahulu diatas maka hipotesis kedua sebagai berikut: 
H2: Brand Image berpengaruh terhadap Keputusan Pembelian

\subsubsection{Pengaruh Celebrity Endorser dan Brand Image Terhadap Keputusan Pembelian}

Celebrity Endorser yang memiliki popularitas yang tinggi, kreadibilitas, bakat dan karisma memberikan manfaat bagi perusahaan. Tantangan besar yang harus dilakukan oleh pemasar adalah membentuk Brand Image yang kuat, sehingga Brand Image dapat mempengaruhi keputusan pembelian konsumen. Ketika konsumen mulai yakin dengan pilihannya terhadap produk, maka akan muncul sikap ingin memiliki dengan muncul niat pembelian dan akhirnya konsumen akan melakukan keputusan pembelian.

Adapun penelitian yang dilakukan Yohanes Aditya (2016), dengan judul "Pengaruh Celebrity Endorser Cristiano Ronaldo dan Brand Image Terhadap Keputusan Pembelian Konsumen Shampoo Clear di Surabaya, menyatakan bahwa Celebrity Endorser dan Brand Image berpengaruh terhadap Keputusan Pembelian.

Berdasarkan teori dan penelitian terdahulu maka hipotesis ketiga sebagai berikut: H3: Celebrity Endorser dan Brand Image berpengaruh terhadap Keputusan Pembelian.

\section{METODE PENELITIAN}

\subsection{Populasi, Sampel, Jenis Data}

Dalam penelitian ini, populasi yang memenuhi karakteristik yang sudah ditentukan bahwa orang yang membeli kopi Luwak White koffie dalam kurun waktu 1 bulan dengan rata-rata jumlah sebanyak 120 pembeli. Sampel ditentukan dengan Rumus slovin, dengan jumlah sebanyak 55 orang,data yang digunakan adalah data primer dan data sekunder.

\subsection{Metode Pengumpulan Data}

Metode Pengumpulan data dalam penelitian ini menggunakan kuesioner, pengumpulan data dengan cara mengajukan pertanyaan secara tertulis guna memperoleh tentang tanggapan konsumen terhadap pengaruh Celebrity Endorser dan Brand Image terhadap Keputusan Pembelian Luwak White Koffie yang telah dilakukan oleh responden. Dan Wawancara, Dari data yang saya dapatkan dari wawancara kepada para pemilik Warung Nasi Pemalang di Jakarta Timur, Penulis mendapatkan informasi bahwa pembelian/peminat produk Luwak White Koffie kurang begitu banyak peminatnya jika dibandingkan dengan produk kopi lain.

\subsection{Metode Analisis Data} T dan Uji F

Penelitian ini menggunakan model Regresi, Korelasi, Koefisien Determinasi, Uji

\section{HASIL DAN PEMBAHASAN}

\subsection{HASIL}

\subsubsection{Analisis Statistik Deskriptif}

Celebrity Endoreser, pernyataan dalam kuesioner yang memiliki presentase tertinggi menyatakan Setuju sebesar 64\% dengan pernyataan "Bintang iklan (Selebriti) mampu membawakan iklan isi pesan dari Luwak White Koffie" 
Brand Image, pernyataan dalam kuesioner yang memiliki presentase tertinggi menyatakan Setuju Sebesar 62\% dengan pernyataan "Kemasan Luwak White Koffie praktis sehingga dapat dikosumsi oleh siapa saja"

Keputusan Pembelian, pernyataan dalam kuesioner yang memiliki presentase tertinggi menyatakan Setuju sebesar 62\% dengan pernyataan "Saya akan selalu membeli Luwak White Koffie"

\subsubsection{Analisis Regresi}

\section{Celebrity Endorser dan Keputusan Pembelian}

\begin{tabular}{|c|c|c|c|c|c|}
\hline \multirow[b]{2}{*}{ Model } & \multicolumn{2}{|c|}{$\begin{array}{l}\text { Unstandardized } \\
\text { Coefficients }\end{array}$} & \multirow{2}{*}{$\begin{array}{c}\text { Standardized } \\
\text { Coefficients } \\
\text { Beta } \\
\end{array}$} & \multirow[b]{2}{*}{$\mathrm{t}$} & \multirow[b]{2}{*}{ Sig. } \\
\hline & B & Std. Error & & & \\
\hline (Constant) & 25,070 & 4,017 & & 6,241 & , 000 \\
\hline Celebrity Endorser & ,134 &, 092 & ,197 & 1,459 & ,150 \\
\hline
\end{tabular}

Analisis regresi sederhana antara $\mathrm{X} 1$ dan $\mathrm{Y}$ didapatkan persamaan regresi: $\mathrm{Y}=25,070+$ 0,134 X1

\section{Brand Image dan Keputusan Pembelian}

\begin{tabular}{|c|c|c|c|c|c|}
\hline \multirow[b]{2}{*}{ Model } & \multicolumn{2}{|c|}{ Unstandardized Coefficients } & \multirow{2}{*}{$\begin{array}{c}\text { Standardized } \\
\text { Coefficients } \\
\text { Beta } \\
\end{array}$} & \multirow[b]{2}{*}{$\mathrm{t}$} & \multirow[b]{2}{*}{ Sig. } \\
\hline & $\mathrm{B}$ & Std. Error & & & \\
\hline (Constant) & 20,891 & 3,750 & & 5,571 & ,000 \\
\hline Brand Image & ,227 & , 085 & (345 & 2,679 & ,010 \\
\hline
\end{tabular}

Analisis regresi sederhana antara X2 dan Y didapatkan persamaan regresi: $Y=20,891+$ $0,227 \mathrm{X} 2$

Celebrity Endorser,Brand Image dan Keputusan Pembelian

\begin{tabular}{|c|c|c|c|c|c|c|}
\hline \multirow{2}{*}{\multicolumn{2}{|c|}{ Model }} & \multicolumn{2}{|c|}{ Unstandardized Coefficients } & \multirow{2}{*}{$\begin{array}{c}\text { Standardized } \\
\text { Coefficients } \\
\text { Beta } \\
\end{array}$} & \multirow[b]{2}{*}{$t$} & \multirow[b]{2}{*}{ Sig. } \\
\hline & & $\mathrm{B}$ & Std. Error & & & \\
\hline \multirow[t]{3}{*}{1} & (Constant) & 19,938 & 4,514 & & 4,417 &, 000 \\
\hline & Celebrity Endorser & 038 & 099 & ,056 & ,386 & ,701 \\
\hline & Brand Image & 211 & 095 & ,321 & 2,219 & ,031 \\
\hline
\end{tabular}

Analisis regresi berganda antara X1, X2 dan Y didapatkan persamaan regresi: $Y=19,938$ $+0,038 \mathrm{X} 2+0,211$. 


\subsubsection{Analisi Korelasi}

\section{Celebrity Endorser dan Keputusan Pembelian}

\begin{tabular}{|c|c|c|c|c|c|c|c|c|c|}
\hline \multirow[b]{2}{*}{$\begin{array}{l}\text { Mod } \\
\text { el }\end{array}$} & \multirow[b]{2}{*}{$\mathrm{R}$} & \multirow[b]{2}{*}{$\begin{array}{c}\mathrm{R} \\
\text { Square }\end{array}$} & \multirow[b]{2}{*}{$\begin{array}{l}\text { Adjusted R } \\
\text { Square }\end{array}$} & \multirow{2}{*}{$\begin{array}{l}\text { Std. Error } \\
\text { of the } \\
\text { Estimate }\end{array}$} & \multicolumn{5}{|c|}{ Change Statistics } \\
\hline & & & & & $\begin{array}{c}\text { R Square } \\
\text { Change }\end{array}$ & $\begin{array}{c}\mathrm{F} \\
\text { Change }\end{array}$ & df1 & df 2 & $\begin{array}{c}\text { Sig. F } \\
\text { Change }\end{array}$ \\
\hline 1 &, $197^{\mathrm{a}}$ & ,039 & ,020 & 1,24687 & ,039 & 2,130 & 1 & 53 & ,150 \\
\hline
\end{tabular}

Besaran Celebrity Endorser dan Keputusan Pembelian, nilai koefisien korelasinya ialah 0,197 , hal ini juga menunjukan bahwa adanya korelasi yang rendah dan positif.

\section{Brand Image dan Keputusan Pembelian}

\begin{tabular}{|c|c|c|c|c|c|c|c|c|c|}
\hline \multirow[b]{2}{*}{$\begin{array}{c}\text { Mode } \\
1\end{array}$} & \multirow[b]{2}{*}{$\mathrm{R}$} & \multirow[b]{2}{*}{$\begin{array}{c}\mathrm{R} \\
\text { Square }\end{array}$} & \multirow[b]{2}{*}{$\begin{array}{c}\text { Adjusted R } \\
\text { Square }\end{array}$} & \multirow{2}{*}{$\begin{array}{l}\text { Std. Error } \\
\text { of the } \\
\text { Estimate }\end{array}$} & \multicolumn{5}{|c|}{ Change Statistics } \\
\hline & & & & & $\begin{array}{l}\text { R Square } \\
\text { Change }\end{array}$ & $\begin{array}{c}\mathrm{F} \\
\text { Change }\end{array}$ & df1 & $\mathrm{df} 2$ & $\begin{array}{c}\text { Sig. F } \\
\text { Change }\end{array}$ \\
\hline 1 &, $345^{\mathrm{a}}$ & ,119 & ,103 & 1,19344 &, 119 & 7,177 & 1 & 53 &, 010 \\
\hline
\end{tabular}

Besaran Brand Image dan Keputusan Pembelian, nilai koefisien korelasinya ialah 0,345, hal ini juga menunjukan bahwa adanya korelasi yang rendah dan positif.

\section{Celebrity Endorser,Brand Image dan Keputusan Pembelian}

\begin{tabular}{|c|c|c|c|c|c|c|c|c|c|}
\hline \multirow[b]{2}{*}{$\begin{array}{l}\text { Mod } \\
\text { el }\end{array}$} & \multirow[b]{2}{*}{$\mathrm{R}$} & \multirow[b]{2}{*}{$\begin{array}{c}\mathrm{R} \\
\text { Square }\end{array}$} & \multirow[b]{2}{*}{$\begin{array}{l}\text { Adjusted } \\
\text { R Square }\end{array}$} & \multirow{2}{*}{$\begin{array}{l}\text { Std. Error } \\
\text { of the } \\
\text { Estimate }\end{array}$} & \multicolumn{5}{|c|}{ Change Statistics } \\
\hline & & & & & $\begin{array}{c}\text { R Square } \\
\text { Change }\end{array}$ & $\begin{array}{c}\text { F } \\
\text { Change }\end{array}$ & df1 & df2 & $\begin{array}{l}\text { Sig. F } \\
\text { Change }\end{array}$ \\
\hline 1 &, $349^{\mathrm{a}}$ & ,122 & ,088 & 1,20313 & ,122 & 3,605 & 2 & 52 & ,034 \\
\hline
\end{tabular}

Besarnya hubungan antara Celebrity Endorser dan Brand Image adalah sebesar 0,349. Hal ini menunjukan pengaruh yang rendah dan positif.

\subsubsection{Koefisien Determinasi}

\begin{tabular}{|l|r|r|r|r|}
\hline Model & \multicolumn{1}{|c|}{$\mathrm{R}$} & R Square & \multicolumn{1}{|c|}{$\begin{array}{c}\text { Adjusted R } \\
\text { Square }\end{array}$} & $\begin{array}{c}\text { Std. Error of the } \\
\text { Estimate }\end{array}$ \\
\hline 1 &, $349^{\mathrm{a}}$ &, 122 &, 088 & 1,203 \\
\hline
\end{tabular}

Kontribusi Celebrity Endorser dan Brand Image terhadap Keputusan Pembelian ditunjukan koefisien determinasi $\mathrm{R}$ squer $=0,122$ artinya presentase sumbangan pengaruh variabel X terhadap Y sebesar 12,2\% sedangkan sisanya sebesar 87,8\% dipengaruhi oleh variabel lain yang tidak dibahas dalam penelitian ini. 


\subsubsection{Uji Hipotesis}

Uji T

\begin{tabular}{|c|c|c|c|c|c|c|}
\hline \multirow{2}{*}{\multicolumn{2}{|c|}{ Model }} & \multicolumn{2}{|c|}{ Unstandardized Coefficients } & \multirow{2}{*}{$\begin{array}{c}\text { Standardized } \\
\text { Coefficients }\end{array}$} & \multirow[b]{2}{*}{$t$} & \multirow[b]{2}{*}{ Sig. } \\
\hline & & $\mathrm{B}$ & Std. Error & & & \\
\hline \multirow[t]{3}{*}{1} & (Constant) & 19,938 & 4,514 & & 4,417 &, 000 \\
\hline & Celebrity Endorser &, 038 & 099 & ,056 & ,386 & ,701 \\
\hline & Brand image & 211 & ,095 & 321 & 2,219 & ,031 \\
\hline
\end{tabular}

a. Celebrity Endorser

Berdasarkan tabel 4.48 diperoleh taraf signifikan Celebriti Endorser sebesar 0,701 dan thitung sebesar 0,386 menunjukkan bahwa tingkat signifikansi 0,701 >0,05 dan thitung 0,386 < tabel 2.007 (Dari daftar T tabel). Kesimpulan: variabel Celebrity Endorser (H1) tidak berpengaruh signifikan terhadap Keputusan Pembelian.

\section{b. Brand Image}

Berdasarkan tabel 4.50 diperoleh taraf signifikan Brand Image sebesar 0,031 dan $t_{\text {hitung }}$ sebesar 2,219 menunjukkan bahwa tingkat signifikansi 0,031 $<0,05$ dan $\mathrm{t}_{\text {hitung }}$ 2,219 $>\mathrm{t}_{\text {tabel }} 2.007$ (Dari daftar T tabel) Kesimpulan: variabel Brand image $\left(\mathrm{H}_{2}\right)$ berpengaruh positif dan signifikan terhadap Keputusan Pembelian.

Uji F

\begin{tabular}{|ll|r|r|r|r|r|}
\hline Model & & Sum of Squares & df & Mean Square & F & Sig. \\
\hline 1 & Regression & 10,438 & 2 & 5,219 & 3,605 &, $034^{\mathrm{b}}$ \\
& Residual & 75,271 & 52 & 1,448 & & \\
Total & 85,709 & 54 & & & \\
\hline
\end{tabular}

Diperoleh taraf signifikan sebesar 0,034 dan $f_{\text {hitung }}$ 3,605 menunjukkkan bahwa tingkat signifikan 0,034<0,05 dan $\mathrm{f}_{\text {hitung }} 3,605>\mathrm{f}_{\text {tabel }}$ 3,17 (Dari daftar $\mathrm{F}$ tabel) maka dapat disimpulkan bahwa Ha diterima, artinya bahwa Celebrity Endorser dan Brand Image secara bersama-sama berpengaruh signifikan terhadap Keputusan Pembelian.

\subsection{PEMBAHASAN}

\subsubsection{Pengaruh Celebrity Endorser terhadap keputusan Pembelian}

Dengan taraf signifikan Celebriti Endorser sebesar 0,701 dan thitung sebesar 0,386 menunjukkan bahwa tingkat signifikansi $0,701>0,05$ dan $t_{\text {hitung }} 0,386<t_{\text {tabel }} 2.007$. Kesimpulan: variabel Celebrity Endorser tidak berpengaruh signifikan terhadap Keputusan Pembelian. Kotler dan Keller (2016:202) mengemukakan bahwa pemasar harus memberi konsumen sesuatu isyarat positif agar konsumen selalu mengingat merek tersebut, dengan penggunaan Celebrity Endorser, kemasan yang menarik, dan promosi yang menarik diharapkan konsumen dapat mengingat suatu merek. 
Penelitian sebelumnya yang dilakukan Iqbal Firdaus (2015), Pengaruh Celebrity Endorser terhadap Keputusan Pembelian Mahasiswa Universitas Widiyatama pada Brodo Footwear Bandung. Hal ini menunjukan tidak adanya keselarasan antara hasil penelitian sebelumnya dengan penelitian ini bahwa tidak terdapat Pengaruh Celebrity Endorser terhadap Keputusan Pembelian. Dalam membintangi iklan Luwak White Koffie, Celebrity Endorser tidaklah membuat konsumen menjadi memutuskan untuk membeli produk yang diiklannya, hal ini dikarenakan dalam melakukan keputusan pembelian konsumen lebih mengedepankan faktor diluar Celebrity Endorser yaitu cita rasa dan harga.

\subsubsection{Pengaruh Brand Image terhadap Keputusan Pembelian}

Dengan taraf signifikan Brand Image sebesar 0,031 dan thitung sebesar 2,219 menunjukkan bahwa tingkat signifikansi 0,031 $<0,05$ dan $t_{\text {hitung }} 2,219>t_{\text {tabel }} 2.007$. Kesimpulan: variabel Brand image berpengaruh positif dan signifikan terhadap Keputusan Pembelian.

Tjiptono (2015:49) menyatakan bahwa "Brand Image ialah deskripsi asosiasi dan keyakinan konsumen terhadap merek tertentu". Penelitian sebelumnya yang dilakukan oleh Sri Nuryani (2014), Analisis Pengaruh Iklan, Citra Merek dan Harga terhadap Keputusan Pembelian Sampo Sunsilk di Semarang. Hal ini menunjukan adanya keselarasan antara hasil penelititian sebelumnya dengan penelitian ini bahwa terdapat pengaruh antara Brand image terhadap Keputusan Pembelian. Hal ini menunjukan bahwa Brand image dari Luwak White koffie membuat konsumen menjadi memutuskan untuk membeli produk Luwak White Koffie, hal ini disebabkan karena kopi luwak identik dengan kopi kualitas tinggi dengan harga yang mahal, dengan Luwak White Koffie, Kopi Luwak ini bisa dijangkau masyarakat dengan harga murah dan mudah ditemui.

\subsubsection{Pengaruh Celebrity Endorser dan Brand Image terhadap Keputusan Pembelian.}

Berdasarkan hasil analisa data dan pengujian hipotesis dalam penelitian ini menunjukkan bahwa secara simultan bahwa variabel Celebrity Endorser (X1) dan Brand Image (X2) secara bersama-sama berpengaruh positif dan signifikan terhadap Keputusan Pembelian (Y). Dengan taraf signifikan sebesar 0,034 dan $f_{\text {hitung }} 3,605$ menunjukkkan bahwa tingkat signifikan $0,034<0,05$ dan $\mathrm{f}_{\text {hitung }} 3,605>\mathrm{f}_{\text {tabel }} 3,17$ maka dapat disimpulkan bahwa Ha diterima, artinya bahwa Celebrity Endorser dan Brand Image secara bersama-sama berpengaruh signifikan terhadap Keputusan Pembelian. berdasarkan kedua nilai tersebut maka dapat dinyatakan $\mathrm{H} 3$ diterima, dimana Celebrity Endorser dan Brand Image berpengaruh positif dan signifikan terhadap Keputusan Pembelian.

Celebrity Endorser yang memiliki popularitas yang tinggi, kreadibilitas, bakat dan karisma memberikan manfaat bagi perusahaan. Tantangan besar yang harus dilakukan oleh pemasar adalah membentuk Brand Image yang kuat, sehingga Brand Image dapat mempengaruhi keputusan pembelian konsumen. Ketika konsumen mulai yakin dengan pilihannya terhadap produk, maka akan muncul sikap ingin memiliki dengan muncul niat pembelian dan akhirnya konsumen akan melakukan keputusan pembelian. Penelitian sebelumnya yang dilakukan oleh Yohanes Aditya (2016), Pengaruh Celebrity Endorser Cristiano Ronaldo dan Brand Image Terhadap Keputusan Pembelian Konsumen Shampoo Clear di Surabaya. Hal ini menunjukan adanya keselarasan antara hasil penelititian sebelumnya dengan penelitian ini bahwa terdapat Pengaruh Celebrity 
Endorser dan Brand Image terhadap Keputusan Pembelian. dalam penelitian ini Celebrity Endorser sudah dianggap baik dalam memasarkan produk sehingga berpengaruh positif pada Keputusan Pembelian didukung dengan adanya Brand image yang lebih memberikan pengaruh yang positif terhadap Keputusan Pembelian. Celebrity yang di pilih oleh perusahaan kopi Luwak White Koffie sudah baik dalam membawakan produk dalam iklan sehingga membuat para responden tertarik serta Brand Image Luwak White Koffie dianggap responden lebih baik dari produk kopi sejenis, hal itu menimbulkan keterkaitan konsumen untuk membeli produk.

\section{PENUTUP}

\subsection{Simpulan}

Berdasarkan hasil penelitian dan hasil analisis data yang telah didapat dari Pengaruh Celebrity Endorser dan Brand Image terhadap keputusan Pembelian Luwak White Koffie studi kasus Pada Warung Nasi Pemalang, dapat ditarik kesimpulan sebagai berikut:

\section{Berdasarkan Hasil Regresi}

a. Regresi Sederhana X1 dan Y

Analisis regresi sederhana antara $\mathrm{X} 1$ dan $\mathrm{Y}$ didapatkan persamaan regresi: $\mathrm{Y}=$ $25,070+0,134$ X1. Dari persamaan diatas dapat dijelaskan sebagai berikut :

Nilai a $=25,070$, yaitu bahwa jika tidak ada perubahan dari variabel Celebrity Endorser, maka nilai skor Keputusan Pembelian adalah 25,070.

Nilai $b=0,134$, artinya setiap penambahan satu skor nilai pada Celebrity Endorser, maka Keputusan Pembelian akan mengalami peningkatan skor sebesar 0,134 kali.

\section{b. Regresi Sederhana X2 dan Y}

Analisis regresi sederhana antara $\mathrm{X} 2$ dan $\mathrm{Y}$ didapatkan persamaan regresi: $\mathrm{Y}=$ $20,891+0,227 \mathrm{X} 2$. Dari persamaan diatas dapat dijelaskan sebagai berikut:

Nilai a $=20,891$ yaitu bahwa jika tidak ada perubahan dari variabel Brand Image, maka nilai skor Keputusan Pembelian adalah 20,891.

Nilai $\mathrm{b}=0,227$, artinya setiap penambahan satu skor nilai pada Brand Image, maka Keputusan Pembelian akan mengalami peningkatan skor sebesar 0,227 kali.

\section{c. Regresi Berganda X1,X2 dan Y}

Analisis regresi berganda antara $\mathrm{X} 1, \mathrm{X} 2$ dan $\mathrm{Y}$ didapatkan persamaan regresi: $\mathrm{Y}=$ $19,938+0,038 \mathrm{X} 2+0,211$. Dari persamaan diatas dapat dijelaskan sebagai berikut:

a. Nilai konstanta (a) sebesar 19,938, artinya variabel Celebrity Endorser $\left(\mathrm{X}_{1}\right)$ dan Brand Image $\left(\mathrm{X}_{2}\right)$ adalah 0, maka besar nilai skor Keputusan Pembelian (Y) akan sama dengan nilai konstanta yaitu 19,938.

b. Nilai B variabel Celebrity Endorser $\left(\mathrm{X}_{1}\right)$ adalah 0,038 , itu berarti apabila variabel Celebrity Endorser berubah, maka Keputusan Pembelian akan berubah. Tanda positif menunjukkan bahwa apabila variabel meningkat 1 point maka Celebrity Endorser akan mengalami peningkatan sebesar 0,038 pada saat nilai $\left(\mathrm{X}_{1}\right)=0$

c. Nilai B variabel Brand Image $\left(\mathrm{X}_{2}\right)$ adalah 0,211 , itu berarti apabila variabel Brand Image berubah, maka Keputusan Pembelian akan berubah. Tanda positif menunjukkan bahwa apabila variabel Brand Image meningkat 1 point maka kinerja akan mengalami peningkatan sebesar 0,211 pada saat nilai $\left(\mathrm{X}_{2}\right)=0$. 


\section{Berdasarkan Hasil Korelasi}

a. Korelasi Sederhana X1 dan Y

Besaran Celebrity Endorser dan Keputusan Pembelian, nilai koefisien korelasinya ialah 0,197 , hal ini juga menunjukan bahwa adanya korelasi yang rendah dan positif.

b. Korelasi Sederhana X2 dan Y

Besaran Brand Image dan Keputusan Pembelian, nilai koefisien korelasinya ialah 0,345 , hal ini juga menunjukan bahwa adanya korelasi yang rendah dan positif.

c. Korelasi Berganda X1,X2 dan Y

Besarnya hubungan antara Celebrity Endorser dan Brand Image adalah sebesar 0,349. Hal ini menunjukan pengaruh yang rendah dan positif.

\section{Berdasarkan koefisien Determinasi}

Kontribusi Celebrity Endorser dan Brand Image terhadap Keputusan Pembelian ditunjukan koefisien determinasi $\mathrm{R}$ squer $=0,122$ artinya presentase sumbangan pengaruh variabel $\mathrm{X}$ terhadap $\mathrm{Y}$ sebesar $12,2 \%$ sedangkan sisanya sebesar $87,8 \%$ dipengaruhi oleh variabel lain yang tidak dibahas dalam penelitian ini.

\section{Berdasarkan Uji T dan Uji F}

a. Celebrity Endorser

Berdasarkan taraf signifikan Celebriti Endorser sebesar 0,701 dan thitung sebesar 0,386 menunjukkan bahwa tingkat signifikansi 0,701 >0,05 dan $\mathrm{t}_{\text {hitung }} 0,386$ $<\mathrm{t}_{\text {tabel }} 2.007$ (Dari daftar T tabel). Kesimpulan: variabel Celebrity Endorser $\left(\mathrm{H}_{1}\right)$ tidak berpengaruh signifikan terhadap Keputusan Pembelian.

b. Brand Image

Berdasarkan signifikan Brand Image sebesar 0,031 dan thitung sebesar 2,219 menunjukkan bahwa tingkat signifikansi 0,031 $<0,05$ dan $t_{\text {hitung }} 2,219>t_{\text {tabel }} 2.007$ (Dari daftar T tabel) Kesimpulan: variabel Brand image $\left(\mathrm{H}_{2}\right)$ berpengaruh positif dan signifikan terhadap Keputusan Pembelian.

c. Uji F (simultan)

Berdasarkan taraf signifikan sebesar 0,034 dan $\mathrm{f}_{\text {hitung }}$ 3,605 menunjukkkan bahwa tingkat signifikan 0,034<0,05 dan $\mathrm{f}_{\text {hitung }} 3,605>\mathrm{f}_{\text {tabel }} 3,17$ (Dari daftar $\mathrm{F}$ tabel), artinya bahwa Celebrity Endorser dan Brand Image secara bersama-sama berpengaruh signifikan terhadap Keputusan Pembelian.

\section{Hasil Jawaban Responden}

a) Celebrity Endorser

Berdasarkan pernyataan dalam kuesioner yang memiliki presentase tertinggi menyatakan Setuju sebesar 64\% dengan pernyataan "Bintang iklan (Selebriti) mampu membawakan iklan isi pesan dari Luwak White Koffie"

b) Brand Image

Berdasarkan pernyataan dalam kuesioner yang memiliki presentase tertinggi menyatakan Setuju Sebesar 62\% dengan pernyataan "Kemasan Luwak White Koffie praktis sehingga dapat dikosumsi oleh siapa saja"

c) Keputusan Pembelian 
Berdasarkan pernyataan dalam kuesioner yang memiliki presentase tertinggi menyatakan Setuju sebesar 62\% dengan pernyataan "Saya akan selalu membeli Luwak White Koffie"

\subsection{Saran}

\section{Bagi Perusahaan}

Setelah melakukan penelitian ini dan melihat hasil pembahasan, penulis mengajukan saran atau masukan yang dapat berguna bagi perusahaan.

a. Disarankan bagi perusahaan dalam memilih endorser (selebriti) yang akan menjadi bintang iklannya harus memperhatikan bahwa bintang iklan yang dipilih memiliki citra yang baik agar konsumen percaya dan milih untuk membeli produk.

Berdasarkan pernyataan dalam kuesioner yang memiliki presentase terendah menyatakan Setuju sebesar $45.5 \%$ dengan pernyataan "Bintang iklan (Selebriti) jauh dari gosip miring sehinga dapat dipercaya"

b. Bagi perusahaan diharapkan memilih endorser yang dikenal oleh generasi milenial sehingga akan meningkatkan penjualan poduk Luwak White Koffie di kalangan anak muda dan meningkatkan pendapatan bagi penjual.

c. Bagi perusaan diharapkan terus melakukan inovasi dalam menciptakan varian baru dan menjaga kualitas produk Luwak White Koffie untuk mempertahankan brand image, karena komponen tersebut menjadi salah satu patokan bagi konsumen dalam memutuskan pembelian.

Berdasarkan pernyataan dalam kuesioner yang memiliki presentase terendah menyatakan Setuju sebesar $43.6 \%$ dengan pernyataan "Luwak White Koffie aman dilambung"

d. Disarankan bagi perusahaan dalam memilih (selebriti) yang akan menjadi bintang iklannya harus memperhatikan kecocokan antara endorser dengan klasifikasi produk, contohnya dalam mengiklankan produk ber genre kopi, perusahaan harus mencoba dengan endorser yang memiliki kesamaan menyukai kopi, contohnya barista yang sudah terkenal di indonesia, itu akan meningkatkan kepercayaan terhadap produk lalu memutuskan untuk membeli.

\section{Bagi Peneliti Selanjutanya}

a. Peneliti selanjutnya dapat memperbaiki keterbatasan yang ada dalam penilitian ini denga memperbanyak jumlah sampel dan cara pengambilan data untuk mendapatkan hasil yang menyeluruh.

b. Peneliti selanjutnya diharapkan dapat mengembangkan penelitian dengan meneliti variabel lain yang ada di luar penelitian ini atau dengan mengkombinasikan variabel yang terdapat dalam penelitian ini dengan variabel lain, seperti Harga dan Kualitas Produk. 


\section{REFFERENSI}

Al Quran

Abdullah, Tamrin, dan Francis Tantri. 2018. Manajemen Pemasaran. Cet 7. Depok: Rajawali Pres.

Aditya, Yohanes. 2016. "Pengaruh Celebrity Endorser Cristiano Ronaldo Terhadap Brand Image dan Keputusan Pembelian Konsumen Shampoo Clear di Surabaya".

Belch, George E dan Belch, Macheal A. 2014. Advertising and Promotion An Integrated Marketing Communikations Perpective. Ge Global Edition. New York. Ne Graw-hill.

Damiati, dkk. 2017. Perilaku Konsumen. Edisi 1. Depok: Rajawali Pers.

Firdaus, Iqbal. 2015. "Pengaruh Celebrity Endorser Terhadap Keputusan Pembelian Mahasiswa Universitas Widyatama pada Brodo Footwear Bandung".

Ghozali, Imam. 2013. "Aplikasi Analisis Multivariate Dengan Progam IMB SPSS 21”. Semarang.Universitas Diponegoro.

Hafizah, Dinda Yulia. 2018. "Pengaruh Celebrity Endorser Terhadap Minat Beli Produk Kosmetik WARDAH”..

Hendra, Muhammad David. 2018. "Pengaruh Kreatifitas Iklan melalui pengunaan Endorser Pocari Sweat untuk Aplikasi Smartphone Terhadap Minat Beli Komunitas".

Ismanto, Dedi. 2016. Manajemen Pemasaran Ritel. Riau: PT Victory Inti Multidaya.

Kotler, Philip and Amstrong, Gary. 2018. Principles Of Marketing. Global Edition. Pearson Education

Kotler, Philip and Kevin Lane, Killer. 2016. Marketing Management. 15 ed Pearson Education Limited. New York.

Kotler, Philip dan Gery Amstrong. 2012. Prinsip-Prinsip Pemasaran. Jakarta: Erlanga

Mochamad Fachri, Ferdinan. 2015. "Pengaruh Merek dan Promosi Terhadap Minat Beli Konsumen di PT. Motor Image Batam”. Akademi Akutansi Permata Harapan.

Nuryani, Sri. 2014. “Analisis Pengaruh Iklan, Citra Merek dan Harga terhadap Keputusan Pembelian Sampo Sunsilk di Semarang".

Prasetyadi, Ciptono Wahyu.2017. Komunikasi Penjualan. Jakarta: PT Elex Media Komputindo.

Puspita, Rm. 2017. Cara Laris Jualan Kuliner Via Media Sosial. Yogyakarta: Laksna.

Royan M Frans. 2015. Marketing Celebrities PT Elex Media Komputindo. Jakrta.

Sangadji, Etta Mamang dan Sopiah. 2013. Perilaku Konsumen. Jakarta: Prenadamedia Grup.

Shimp, Terence. A. 2014. Komunikasi Pemasaran Terpadu Dalam Periklanan Promosi. Edisi 8. Salemba Empat. Jakarta 
Siregar, Sofyan. 2017. Metode Penelitian Kuantitatif. Kencana, Jakarta.

Sopiah dan Sangadji, Etta Mamang. 2013. Perilaku Konsumen. Yogyakarta: Andi Offset

Sudiarto, dan Pawana Nur Indah. 2016. Manajemen Pemasaran. Edisi 1. Semesta Anugra.

Sugiyono. 2013. Metode Penelitian Bisnis. Bandung: Alfabet.

Sujarweni.W. 2015, Metode Penelitian Bisnis dan Ekonomi Pendekatan Kuantitatif. Pustaka Baru Pres. Yogyakarta

Sumarwan, Ujang. 2015. Perilaku Konsumen Teori dan Penerapannya. Edisi II. Bogor: Ghalia indonesia.

Sumarwan, Ujang.2015. Perilaku Konsumen. Bogor : Galia Indonesia.

Sunyoto, Danang. 2014. Konsep Dasar Riset Pemasaran \& Perilaku Konsumen, Yogyakarta: Buku Seru.

Sunyoto, 2014, Dasar-Dasar Manajemen Pemasaran (konsep,strategi dan kasus CAPS (Center of Academing Publisbing Servis), Yogyakata.

Tjiptono, Fandy, 2015. Brand Management \& Strategy. Yogyakarta : Andi

Tjiptono, Fandy, dan Gregolius Candra. 2017. Pemasaran Strategik. Edisi 3. Yogyakarta: ANDI.

Tjiptono, Fandy. 2015. Strategi Pemasaran. Edisi 4. Yogyakarta: Andi.

Wulandari, dan Nurcahya. 2015." Pengaruh Celebrity Endorser, Brand Image, Brand Trust Terhadap Keputusan Pembelian Clear Shampoo Di Kota Denpasar". 